\title{
Women and Cardiovascular Disease: Gender-Based Issues Regarding Detection and Primary Prevention
}

\author{
Roseann M. Chesler*, David W. Ho, Keshwar Ramkissoon \\ Department of Cardiovascular Medicine, SUNY Downstate Medical Center, Brooklyn, NY, USA \\ Email: roseann.chesler@downstate.edu
}

Received 20 September 2014; revised 7 November 2014; accepted 20 November 2014

Copyright (C) 2014 by authors and Scientific Research Publishing Inc.

This work is licensed under the Creative Commons Attribution International License (CC BY).

http://creativecommons.org/licenses/by/4.0/

(c) () D Den Access

\begin{abstract}
Society has come a long way over the past several decades from the old fashion belief that cardiovascular disease (CVD) is a man's disease. Throughout the years, gender-based studies have provided compelling evidence to uncover several unique features in disease presentation, pathology and primary prevention in women. Studies reviewing differences among men and women have placed specific emphasis on cardiovascular risk factors, symptoms and vascular pathology as potential etiologies for the higher cardiovascular mortality and disability among women. In addition, although weight loss and exercise have been shown to promote cardiovascular health in men, more recently findings have presented data to support the importance of these interventions among women. Although tremendous strides have been made throughout the years in the genderbased cardiovascular research, more questions than answers remain and additional research efforts are still needed to better understand the disease process in women. The objectives of this review are two-fold: First, to present a comparative analysis focusing on evidence-based similarities and differences among males and females in cardiovascular disease presentation, detection and clinical pathology; Second, to offer insights highlighting recent findings regarding primary prevention and treatment protocols in women. Based on our current knowledge, continued efforts geared toward optimal diagnostic testing and screening protocols for primary disease detection and risk factor modification programs are recommended. This would include further investigations of the potential role that genetics and/or environment play/plays in the natural progression of the disease process. Additionally, comprehensive lifestyle interventions aimed at reducing cardiovascular disability and mortality in women is also recommended.
\end{abstract}

\section{Keywords}

Women, Cardiovascular Disease, Exercise, Risk Factors

\footnotetext{
${ }^{*}$ Corresponding author.

How to cite this paper: Chesler, R.M., Ho, D.W. and Ramkissoon, K. (2014) Women and Cardiovascular Disease: GenderBased Issues Regarding Detection and Primary Prevention. Health, 6, 2790-2801. 


\section{Introduction}

Society has come a long way over the past several decades from the old fashion belief that cardiovascular disease (CVD) is a man's disease, this owing to an overwhelming number of gender-based research findings focusing on disease prevention, pathogenesis and progression in women. As a result of this increased awareness, heart disease has moved to the forefront as a leading cause of disability and death among women, surpassing breast cancer and other cancers combined. It has been reported that 1 of every 31 women die from breast cancer each year and 1 of 3 women die from heart disease [1].

Although evidence from the National Cholesterol Education Panel (NCEPII) has reported a 35\% - 50\% reduction in the cardiovascular death rate over the past several decades, the reduction among women has not yet reached those reported in men [2].

While CVD does affect both genders the problem does not affect them in a similar manner. This is due to several unique features among women with regard to the disease presentation (i.e. risk factors, pathology, and symptoms) and clinical course. While precise mechanisms behind the differences have not yet been elucidated one fact remains; women have a higher cardiovascular mortality and morbidity compared with men.

It was previously observed that disease onset in women generally begins approximately 10 years later compared with men, with the rate increasing following menopause. This may be explained by a greater cluster of risk factors associated with metabolic syndrome in postmenopausal women as well as the gradual removal of the estrogen-provoked cardiovascular protection compared with younger women. Although the lifetime risk of developing CVD is equal between men and women, this risk is generally lower in younger women and it accelerates as a woman approaches menopause, at which point the heart disease risk increases by threefold [3] [4].

More recently, findings have provided alarming evidence to support an increase in the cardiovascular death rate in young women between the ages of 35 - 44 years (1.3\% annually since 1997) [5], and an astounding 69\% percent higher mortality rate among black women compared with white women [2] [6]. This progressively earlier disease onset may be related to changes in modern lifestyle and the fact that younger women appear to focus less on healthy cardiovascular lifestyles compared with their male counterparts. Furthermore, coronary disease often presents atypically in women where they often do not experience typical angina and $50 \%$ of women who had a heart attack reported no chest pain at all thus resulting in a delay in diagnosis and treatment.

When a diagnosis of CVD is made in women, they are noted to have pathologically more severe coronary disease compared with men of the same age and they are more likely to die within the first 2 weeks of a heart attack. Several mechanisms appear to relate to this including differences in vascular size, pathology and function combined with a hormonal influence which further adds to the complexity of diagnosing coronary disease [7].

Additionally, epidemiologic findings have reported that women have a lower prevalence of atrial fibrillation but they have a greater risk for stroke when compared with men [8]. Furthermore, women tend to develop myocardial infarction and heart failure at a later age compared with men, [9] and female patients who suffer from heart failure with preserved ejection fraction may have a survival advantage over the male counterparts in the long term [10] [11]. This suggests a gender difference in disease risk, development and progression.

The purpose of this review is to highlight gender-based similarities and differences in CVD presentation and pathology that have been obtained through the years and to provide insights into primary prevention of CVD in women.

\section{Cardiovascular Risk Factors}

While we have learned and studied the gender differences as they pertain to CVD, there are many unanswered questions. Deeper analyses have extended into genetics. Silander et al. examined men and women in Finland to determine the effects of genetic risk factors versus environment on the development of CVD. Their findings suggested that men are generally affected by both environmental (modifiable risk factors) and genetic factors while genetic factors seem to exert a greater influence among women [12].

Several studies have looked at gender differences in the early onset of disease pathology by focusing on traditional risk factor profiles between men and women. While the prevalence of traditional risk factors such as hypertension, diabetes, obesity and sedentary lifestyle occur with a higher frequency in women [13] the incidence of many of these risk factors accelerates as women age [14] [15]. At the same time risk factors such as dyslipidemia and tobacco are noted to be less prevalent among women [16]. Furthermore, although obesity is associated with an increase in other disease risk factors, neither body mass index (BMI) nor abdominal obesity 
was independently associated with coronary artery disease or cardiovascular events in women [17].

The cardiometabolic effects of diabetes in women appear different compared with men. In a recent metaanalysis of 64 cohorts, involving 900,000 patients, Peters et al., demonstrated that women with diabetes on average showed a 2.63 (95\% CI 2.27 to 3.06) fold increase in relative risk, whereas men with diabetes showed a 1.85 (95\% CI 1.64 to 2.10) fold increase in relative risk for coronary heart disease. This translates to a $44 \%$ greater increase in relative risk for coronary heart disease in women with diabetes compared to men [18]. A second meta-analysis examining 64 cohorts with 777,385 individuals by the same author showed a 25\% increase in relative risk for stroke in women compared with men with diabetes [19] emphasizing the differential effects of diabetes on vascular health in women compared with men. The authors further suggest that this difference may be secondary to differences between men and women in level of metabolic changes needed to occur prior to sufficient impairment in glucose tolerance in women for the diagnosis of diabetes, thus more women spend a greater amount of time in the pre-diabetic state when compared with men [18].

Asaff et al. in their study involving a large cohort of young men and women (mean age 35 yrs) noted that women were more likely to participate in risk factor prevention programs compared with men for smoking cessation, weight loss and physical activity. As for the success rate for risk factor management, men appeared to be more successful at smoking cessation and both groups had similar success rates for weight loss and increased physical activity. However, an 8-year follow-up in men showed that they achieved significantly more weight loss compared with women [20].

Despite the increased prevalence of traditional risk factors, women with ischemic heart disease in general are older and tend to have more comorbidities compared with men, consistent with previously mentioned genetic findings, this observation suggests that women may be affected to a lesser extent or differently when compared with men by these traditional risk factors [21] [22].

\section{Diagnostics}

Although there has been an improvement in the recognition of non-fatal CVD among women in the past decade [23], ischemic heart disease is still diagnosed less in younger women and more often in older women compared with men [24]-[26]. A lower diagnostic rate in younger women could be related to the lower disease burden in this population. Alternatively, the disease may not have been detected or expected and sought after in a young individual. Clinical procedures used to identify the presence of CVD in women has become a major challenge for physicians because the traditional diagnostic non-invasive screening tools are less sensitive and specific in females, and women do not always experience the "typical chest pain" compared with the classic disease presentation in men [27]-[29].

Until recently, very little was known about the early warning signs of heart disease in women with regards to symptoms. More women present with atypical symptoms prior to or during a myocardial infarction (MI) compared with men. While men typically present with chest discomfort, the most common complaints during an MI in women include: shortness of breath (58\%), weakness (55\%) and unusual fatigue (43\%), with nearly two thirds of death associated with an MI in women occurring in those with no prior history of chest pain.

Mc Sweeny et al. noted that between $80 \%$ - $85 \%$ of women reported a vast array of prodromal symptoms one month prior to their MI including: shortness of breath, unusual fatigue, indigestion, anxiety, arms weak and heavy, or sleep disturbances. When they examined acute symptoms they found that chest pain was also feeling uncommon. As a result of this, the early recognition of a coronary event is not as straightforward in women as it is for men [30].

In the setting of acute coronary syndrome, it is not unusual to find non-obstructive disease on coronary angiography and despite having less obstructive CAD, women have a poorer prognosis. This has been attributed to advance age, multiple comorbidities and underutilization of life saving therapies at the time of disease detection [31].

Among those women with non-obstructive disease who actually present with chest pain the majority may continue to have persistent chest pain necessitating hospitalization, repeated stress testing and in some cases coronary angiogram, adding to an increased financial burden with no further benefit. Data from the Women's Ischemia Syndrome Evaluation Study (WISE) showed a deteriorating mortality and adverse cardiovascular events for these women when compared to those who are asymptomatic [32].

Women who experience chest pain and other heart symptoms are more likely than men to have coronary microvascular disease (MVD). MVD may be associated with Syndrome-X or non-obstructive epicardial coronary 
artery disease, and it presents as a form of atherosclerosis affecting the walls of the small vessels which branch from the major epicardial coronary arteries resulting in a reduction in blood flow to the heart. MVD when present in the retinal artery has been shown to be associated with CVD events in women, but not men [33].

There is emerging data to support a gender specific role for MVD. In comparison to men autopsy data has shown that women have more microvascular plaque erosion and distal embolization compared with men [34]. MVD is common in approximately $50 \%-60 \%$ of symptomatic younger women and $20 \%$ of men. Knowing that women usually present with atypical symptoms, the data suggest that when they do present with chest pain it is possibly due to MVD rather than obstructive epicardial coronary artery disease. This may warrant a different approach to the disease detection and management for those women. As a result of the higher prevalence of MVD in women, they are more affected by cardiovascular risk factors such as hypertension, diabetes mellitus and smoking compared with men. This condition is a possible explanation for the poorer CVD prognosis among women.

In a study done to examine intravascular ultrasound and coronary reactivity testing in men and women, the results showed that women have less obstructive epicardial coronary disease even when they present with chest pain suggesting prevailing MVD [35]. Furthermore, recent results from the OCTAVIA study showed that patients with acute ST elevation myocardial infarction did not differ compared with men for culprit plaque morphology and vascular healing in response to stent placement or clinical outcome. This raises the question as to major differences between men and women being secondary to risk factors associated with microvascular health rather than macrovascular disease [36].

Traditional non-invasive diagnostic testing currently in use for detecting coronary artery disease is not optimal for the detection of MVD. Other alternative screening tests are currently being evaluated. The assessment of vascular reactivity has become an important research tool in cardiovascular medicine and endothelial dysfunction has become a growing topic as such is considered a surrogate to CVD. The assessment of the peripheral endothelial response along with a direct assessment in coronary circulation has been shown to be associated with ischemic heart disease risk.

Endothelial function reflects the health of regional and to some extent the total vascular bed and as such endothelial dysfunction is an important prognostic indicator. Healthy endothelial function allows for an adaptive vascular response and it plays a role in cardio protection against ischemic injury. In men endothelial dysfunction will present itself earlier compared with women and a steep decline in endothelial function occurs in women following menopause [37] [38].

Skaug et al. studied the association between cardiovascular risk factors and endothelial function in more than 2500 women and 2200 men. They noted that endothelial dysfunction occurred twice as frequently among women with hyperglycemia compared with men and the presence of metabolic syndrome, hypertension and poor exercise capacity increased the prevalence of endothelial dysfunction more in women than men [39]. In addition, postmenopausal women who were treated with antihypertensive therapy for 6 months significantly improved their endothelial function and prognosis [40].

Although these newer technologies have provided greater insight into disease pathology, further data are needed to devise the most effective means for detecting and diagnosing both macrovascular and microvascular coronary disease in women. Based on current research the area of concentration should relate to strategies involving the measurement of vascular reactivity and non-invasive surrogate measurements.

\section{Preventive Strategies: Weight Loss and Exercise the Perfect Combination}

Several prominent scientific organizations such as the National Heart Lung and Blood Institute, American Heart Association, American Diabetes Association and the American College of Cardiology have outlined preventive measures aimed at promoting cardiovascular health. In general, the major cornerstone of their recommendations for primary prevention is to adopt healthy lifestyles which includes: refraining from smoking, maintaining a desirable body weight (BMI 18.5 - $24.9 \mathrm{~kg} \cdot \mathrm{m}^{2}$ with a waist circumference of $\leq 35$ inches in women), regularly exercising (a minimum of 30 min of moderate exercise most or all days of the week) and incorporating healthy dietary habits ( $<10 \%$ saturated fat calories, $<300 \mathrm{mg}$ cholesterol and substituting trans-fatty acids for fruits, veggies and grains) [41].

Weight loss and physical activity are two important areas for targeting cardiovascular risk factor management. The National Heart, Lung and Blood Institutes (NHLBI) 2010 statistics reported a slightly higher rate of obesity in US women (38.8\%) compared with men (35\%). More importantly, women between the ages of 20 and 60 
have a higher rate of obesity compared with aged-matched males. The obesity rate for minorities is higher, with $45 \%$ of Mexican-American and 54\% of black women reportedly being overweight or obese. In addition, African American women have a startling 50\% higher obesity rate compared with age and ethnic matched males [1].

\section{Physical Activity and CV Mortality}

An overwhelming body of evidence has been presented to document the inverse relationship between exercise capacity, cardiovascular and all-cause mortality and morbidity among men.

Data dating back to the earlier studies by Paffenbarger on 17,000 male college alumni, those who walked a distance of 9 or more miles per week had a $21 \%$ lower mortality rate compared with those who walked 3 miles per week or less [42].

Although the mortality-physical activity relationship has been well documented, it still remains unclear as to the precise mechanism by which there is a cardiovascular risk reduction.

In the past there was a great deal of uncertainty regarding the association between physical activity and cardiovascular mortality among women and minorities. Prior to the late 1980's women were under-represented in epidemiologic studies for CVD prevention. Over the past few years, investigators have begun to examine the role of exercise in the primary prevention of cardiovascular disease in women (summary on Table 1).

The findings reported in large cohort studies such as the Women's Health Initiative, Women Take Heart

Table 1. Evidence-based results for primary prevention of cardiovascular disease in women.

\begin{tabular}{|c|c|c|c|c|c|c|}
\hline Author (year) & $\mathbf{N}$ & Gender(M/F) & Mean age & $\begin{array}{l}\text { Follow-up } \\
\text { time (yrs) }\end{array}$ & $\begin{array}{l}\text { Exercise } \\
\text { modality }\end{array}$ & Results \\
\hline Lee (2001) & 39,372 & $\mathrm{~F}$ & $47-60$ & 3 & Walking & $\begin{array}{c}1 \text { hour walking per week light-to-moderate } \\
\text { lowered CHD rates. Inverse relation also showed } \\
\text { in those at risk for CVD } \\
\text { (overweight, increased cholesterol levels, } \\
\text { smokers) }\end{array}$ \\
\hline Manson (2002) & 73,743 & $\begin{array}{c}\text { F } \\
\text { Postmenopausal }\end{array}$ & $50-79$ & 8 & Walking & $\begin{array}{c}\text { Walking and vigorous exercise substantially } \\
\text { reduced incidence of CV disease. Prolong sitting } \\
\text { increased risk } \\
\text { Inverse relation observed independent of race, } \\
\text { body type and age }\end{array}$ \\
\hline Hu (2004) & 116,564 & $\begin{array}{c}\mathrm{F} \\
\text { Lean } \\
\text { BMI }\left(<25 \mathrm{~kg} \cdot \mathrm{m}^{2}\right) \\
\text { active and inactive } \\
\text { obese } \\
\text { BMI }\left(\geq 30 \mathrm{~kg} \cdot \mathrm{m}^{2}\right) \\
\text { active and inactive }\end{array}$ & $30-55$ & 24 & $\begin{array}{l}\text { Physical activity } \\
\text { recall } \\
\text { time spent per } \\
\text { week } \\
\text { brisk walking, } \\
\text { jogging, cycling } \\
\text { etc. }\end{array}$ & $\begin{array}{c}\text { Excess weight (BMI }>25 \mathrm{~kg} \cdot \mathrm{m}^{2} \text { or higher and } \\
\text { Physical inactivity (less than } 3.5 \text { hours per } \\
\text { week) } \\
\text { accounted for } 31 \% \text { of all premature deaths ( } 59 \\
\text { from CVD) }\end{array}$ \\
\hline Mora (2007) & 27,005 & $\begin{array}{c}\text { F } \\
\text { With and without } \\
\text { CV risk factors }\end{array}$ & $54 \pm 7$ & $10.9 \pm 1.6$ & $\begin{array}{c}\text { Physical activity } \\
\text { kcal/week }\end{array}$ & $\begin{array}{l}\text { Moderate exercise (600kcal/wk equivalent to } 2 \\
\text { hr/wk brisk walking) lower risk of CVD events } \\
\text { Modest changes in risk factors, Inflammation, } \\
\text { blood pressure) } \\
200 \text { - } 599 \mathrm{kcal} / \mathrm{wk}, 600 \text { - } 1499 \mathrm{kcal} / \mathrm{wk} \\
\text { and } \geq 1500 \mathrm{kcal} / \text { wk associated with a } 25 \% \text {, 32\% } \\
\text { and } 41 \% \mathrm{CV} \text { risk reduction, respectively }\end{array}$ \\
\hline Schmitz (2007) & 164 & $\begin{array}{c}\mathrm{F} \\
\text { Overweight and } \\
\text { obese } \\
\text { BMI } 25-35 \mathrm{~kg} \cdot \mathrm{m}^{2} \\
\text { premenopausal }\end{array}$ & $25-44$ & 2 & $\begin{array}{l}\text { Strength training } \\
\qquad 2 \times / \mathrm{wk}\end{array}$ & $\begin{array}{l}\text { Strength training effective for preventing } \\
\text { increase in percentage of body fat and } \\
\text { intra-abdominal fat mass in } \\
\text { Overweight and obese premenopausal women }\end{array}$ \\
\hline $\begin{array}{c}\text { Sattelmair } \\
\text { (2011) } \\
\text { Meta-Analysis }\end{array}$ & $\begin{array}{l}33 \text { Stu- } \\
\text { dies }\end{array}$ & $\mathrm{M}$ and $\mathrm{F}$ & $\begin{array}{l}\text { Adults }> \\
18 \text { years } \\
\text { old }\end{array}$ & 1995-2009 & $\begin{array}{c}\text { Leisure time } \\
\text { physical activity } \\
\text { (min/wk) }\end{array}$ & $\begin{array}{c}\text { Those who engaged in } 150 \mathrm{~min} / \text { wk or more had } \\
\text { a 14\% lower CHD risk compared with sedentary } \\
300 \text { min/wk of moderate intensity leisure } \\
\text { activity modestly lower risk } \\
\text { There was a significant interaction by sex (p = } \\
\text { 0.03); suggesting a stronger relationship among } \\
\text { women }\end{array}$ \\
\hline
\end{tabular}

$\mathrm{F}=$ female; $\mathrm{M}=$ male CHD = coronary heart disease CVD = cardiovascular disease. 
Project and the Lipid Research Clinics Research Prevalence Study have all conferred the inverse and graded association between physical activity and mortality [43]. Data from the Women's Health Initiative reported a 50\% reduction in cardiovascular risk among women who walked 1 - 1.5 hours per week at 50\% of the Surgeon General's recommendation (a total of $150 \mathrm{~min} /$ week of moderate intensity exercise) [44].

Gregg and associates reported that sedentary women who became physically active over a 6-year period of time had a 32\% and a 38\% decline in all-cause and cardiovascular mortality, respectively compared with those who remained sedentary [45]. In fact, there has been some evidence to suggest a greater degree of improvement in women compared with men [46] [47].

Despite the growing body of evidence which reports the inverse relationship between physical activity and cardiovascular risk, $32 \%$ of US adults currently do not engage in at least 10 minutes of light or moderate leisure time activity per day [48] [49].

Data reveal that physical inactivity is higher among women compared with men (33.2\% versus $29.9 \%$ ) with only $21 \%$ of women currently meeting American Heart Association exercise guidelines for improving cardiovascular health. Equally important is the fact that sedentary lifestyle is greatest among minority women and the trend continues to increase as individuals grow older.

It is interesting to note that epidemiologic data from the Centers for Disease Control and Prevention (CDC) combining the obesity rate, physical activity rate and cardiovascular disease rate has demonstrated that in those areas of the United States where the obesity rate is higher than 30\%, the prevalence of adults who do not engage in physical activity was higher than $30 \%$. In addition the CVD death rates in women $35+$ years or older was also greater in those areas as well [50].

\section{Obesity Has No Boundaries}

The distribution of body fat is a major consideration for CVD risk. Abdominal/androidal obesity (apple-shaped) is associated with greater CVD risk compared with gluteal-femoral/gynoidal (pear-shaped) obesity. Obesity increases CVD risk by serving as a precursor to the development of other CVD risk factors such as hypertension and insulin resistance. Women who are overweight have a 3 fold increased risk of diabetes, whereas obesity carries a 9 fold increased risk for the development of diabetes [5].

Prior to menopause, females often store the majority of fat in subcutaneous depots, mainly in the gluteal-femoral region, making them gynoidal or pear-shaped while men store adipose primarily in the abdominal region making them androidal. During menopause, there is a decrease in estrogen production and the ratio of androgen (testosterone) to estrogen increases. Several studies have linked this shift to a potential cause for an increased abdominal fat after menopause. In addition, some studies have also noted that the drop in estrogen is also linked to the increase in cortisol levels (stress hormone which promotes accumulations in abdominal fat or "middle age spread").

Based on the data reported in the Nurse's Health Study, women with a waist circumference greater than $\geq 35$ inches had an increased CV mortality and this relationship existed even among those women who were not overweight. Based on these findings it is safe to assume that the CVD burden from obesity becomes an additional consideration among menopausal women and maintaining a healthy waist size is important [51].

Lovejoy and coworkers reported on the influence of estrogen altering metabolism and visceral fat distribution. Estrogen influences lipoprotein and lipase in adipose tissue, in addition estrogens play an important role in regulating body fat distribution. With abdominal fat on the rise during the peri-menopausal period an increase in visceral abdominal fat is noted in the first 2 years following menopause [52]. Furthermore, recent data suggests that increased visceral adiposity is strongly associated with incident hypertension [53].

\section{Let's Get Physical to Fight the "Battle of the Bulge"}

An important recommendation to combat abdominal obesity is regular-moderate exercise for at least 30 minutes per day. The Studies of Targeted Risk Reduction Interventions through Defined Exercise (STRRIDE) study examined 175 sedentary men and women and they demonstrated equivalence of exercising 11 miles per week, independent of intensity, prevented a significant accumulation of visceral fat with the greatest reduction occurring during vigorous exercise in both groups. More importantly, those who did not exercise experienced a $9 \%$ gain in visceral fat [54].

Schmitz studied 164 overweight and obese (BMI $25-35 \mathrm{~kg} \cdot \mathrm{m}^{2}$ ) premenopausal women between the ages of 
24 - 44 years and found that those women who engaged in strength training an average of one hour twice per week reduced their proportion of abdominal fat by nearly $4 \%$. They were also successful at keeping off visceral fat compared with those who merely received advice concerning exercise [55].

One of the most common misconceptions for abdominal weight loss is to perform sit-ups. Spot reduction will tighten abdominal muscles but it will not reduce visceral fat [56].

\section{Combination Therapy: Exercise and Weight Loss: A Perfect Combination}

Chiuve SE et al. in the prospective Nurse's Health Study demonstrated a lower risk of sudden cardiac death in a large cohort of females who engaged in 30 minutes of physical activity combined with a low risk lifestyle which included a low BMI, and a Mediterranean-type diet [57].

$\mathrm{Hu}$ and coworkers studied a cohort of 116 women age 30 - 55 years and they noted that the combination of physical inactivity (less than 3.5 hours per week of exercise) and excess body weight (BMI of $25 \mathrm{~kg} \cdot \mathrm{m}^{2}$ or higher) were independent predictors of death, accounting for $59 \%$ of deaths from cardiovascular disease [58].

\section{Dose Response Relationship: How Much Is Enough?}

The recommendation for engaging in an exercise program is usually met with reluctance because the mere mention of exercise to most sedentary individuals carries with it an intimidating connotation of marathon running or some other form of high intensity activity. Although an optimal dose for the maximum cardiovascular benefit has not been established, it is of interest to note that exercise consisting of as little as 75 minutes per week has been associated with a significant reduction in cardiovascular risk.

Blair et al. looked at the age-adjusted death rates among 13,000 men and women over an 8-year period. Despite accounting for other risk factors such as smoking, hypertension, hyperlipidemia, family history and diabetes, the death rate was three times higher among the most sedentary males and females $(64 \%$ and $39.5 \%$ deaths per 100,000, respectively) compared with the most active men and women (18.6\% and $8.5 \%$ deaths per 100,000 , respectively). It appeared that as both men and women progressed from sedentary to high levels of fitness the death risk declined, with the greatest benefit occurring when they performed moderate exercise (walking briskly for 30 minutes several times per week) [59].

Sattelmair et al. in their meta-analysis of a cohort of 33 studies including men and women showed that those achieving a program consisting of 75 - $150 \mathrm{~min} /$ week had a 14\% reduction in cardiovascular risk and a higher dose of $300 \mathrm{~min} /$ week reduced cardiovascular risk by $20 \%$. In addition, there was some evidence to suggest that the risk reduction in women was greater compared with men [60].

Manson et al. examined the role of walking and vigorous exercise on CVD prevention in a large group of postmenopausal women of various ethnic and minority groups. They noted a similar beneficial CV effect for both walking and vigorous exercise without differences among the groups and this benefit was demonstrated across ethnic and racial backgrounds, age and BMI. In addition, those who were sedentary had an increased CV risk [61].

\section{Activity Tracking: The "New Wave" for Enhancing Physical Activity}

The new innovation for physical activity monitoring is the activity tracker. Unlike your standard pedometer which monitors physical activity level with steps per day, the activity tracker will monitor activity level through steps per day, calories burned, metabolic rate, heart rate and sleep pattern.

Luke et al. in their cross-sectional study of men and women 20 - 65 years old showed an inverse relationship between minutes of moderate and vigorous exercise using an activity tracker and systolic blood pressure, blood glucose, and BMI. They also demonstrated a positive relationship between activity level and high density lipoprotein cholesterol [62].

\section{What about Hormone Replacement?}

The utility of hormone replacement therapy (HRT) for reduction of cardiovascular disease in women remains of great interest. Estrogen is known to modulate risk factors for CAD including hypertension and hyperlipidemia. The effects of estrogen includes but is not limited to a reduction in the level of Endothelin-1 which results in vasodilation as well as the up regulation of lipoprotein lipase which leads to break down of VLDL. The results 
of clinical trials utilizing HRT have been mixed. The Women's Health Initiative (WHI) was terminated early when HRT with combined estrogen and progesterone resulted in greater breast cancer, pulmonary embolism, stroke and cardiovascular events [63]. This was followed by the Heart and Estrogen/Progestin Replacement Study (HERS) where women receiving HRT were found to have a 52\% increase in cardiovascular events [64]. The findings within these studies were later affirmed by the Estrogen in Prevention of Reinfarction Trial (ESPRIT) [65], Estrogen Replacement and Atherosclerosis (ERA) trial and the Women's Angiographic Vitamin and Estrogen (WAVE) trials. Despite negative results in the prior studies, recent evidence suggests not all is lost. Schierbeck et al. in their study examining HRT in the recently post-menopausal female demonstrated a reduction in mortality, myocardial infarction and heart failure without an increase in the previously noted adverse events of cancer, venous thromboembolism or stroke [66]. However, this is a single study and this result needs to be taken with caution and additional long term trials needs to be performed before HRT could be recommended.

\section{Conclusions}

Scientific research is only beginning to uncover the unique features associated with CVD among women and female minorities by examining differences in the biological, pathophysiological and therapeutic areas.

To date, we have managed to identify the following unique characteristics among women:

- An increased awareness of the crucial role that diabetes mellitus plays in the disease process and the higher cardiovascular mortality and morbidity in women with diabetes. This has resulted in a more aggressive approach focused at primary prevention programs particularly among those women at risk of developing diabetes mellitus.

- Identification of non-traditional symptoms that precede a cardiovascular event in women. This has not only made the diagnosis of the disease a more complex process, it has resulted in a more tailored approach for detecting CVD.

- As a result of the greater prevalence of MVD among women, especially those with chronic chest pain, a redirected approach for diagnostic testing and the clinical management of vascular disease among this patient population has been made.

- Finally, the cardiovascular benefits associated with an active lifestyle have been revealed. In fact, there is some evidence to suggest a slightly greater benefit compared with men. Additionally, the dose response relationship between exercise and cardiovascular health has been well documented in women and findings suggest that moderate and even low intensity exercise has been shown to play an important role in primary prevention.

The hope for the future is for the medical community to continue to increase the awareness regarding the clinical features associated with CVD in women as well as emphasizing optimal and comprehensive prevention programs geared toward women and female minorities.

\section{Recommendations}

Based on the findings presented in this review, the following are recommended:

1) Although little could be done about the genetics, risk factor lifestyle modification would be of central importance for primary prevention. Given the significant risk that diabetes imposes on coronary disease, diabetes prevention with diet and exercise may prove to be the optimal means for ameliorating diabetes and at the same time reduce other traditional cardiovascular risk factors that are associated with the development of CAD and improved endothelial health. Furthermore, although HRT may eventually prove to be of benefit, given the current available evidence HRT should not be routinely recommended.

2) Women with acute coronary syndrome may not present with the classic anginal symptoms, more awareness of the "atypical" symptoms by both the medical practitioner and the general public is needed. Furthermore, a thorough investigation with optimal diagnostic procedures and detailed physical examination may prevent delay in the treatment of potential fatal myocardial infarctions. Despite the fact that women have a lower prevalence of coronary disease at a younger age compared with men, this should not deter guideline directed management.

3) Total body fat is important for several risk factors, however a greater emphasis should be on maintaining a healthy waist circumference and a reduction in visceral adiposity as this becomes more crucial among peri-menopausal and postmenopausal women. 
4) You do not have to run marathons or perform intensive exercise to obtain the cardiovascular benefits. The findings in women support a beneficial effect with moderate walking. The emphasis should be on consistency and regularity.

\section{References}

[1] Go, A.S., et al. (2013) Heart Disease and Stroke Statistics-2013 Update a Report from the American Heart Association. Circulation, 127, e6-e245. http://dx.doi.org/10.1161/CIR.0b013e31828124ad

[2] Mosca, L., Barrett-Connor, E. and Wenger, N.K. (2011) Sex/Gender Differences in Cardiovascular Disease Prevention: What a Difference a Decade Makes. Circulation, 124, 2145-2154. http://dx.doi.org/10.1161/CIRCULATIONAHA.110.968792

[3] Williams, R.A. (2009) Cardiovascular Disease in African American Women: A Health Care Disparities Issue. Journal of the National Medical Association, 101, 536-540.

[4] Garber, C.E. and Pescatello, L.S. (2014) ACSM Current Comments. American College of Sports Medicine 2014.

[5] Kannel, W.B. and Wilson, P.W. (1995) Risk Factors That Attenuate the Female Coronary Disease Advantage. Archives of Internal Medicine, 155, 57-61. http://dx.doi.org/10.1001/archinte.1995.00430010063008

[6] Neils, E. and Wenger, N.K. (2008) Cardiovascular Disease Prevention Tailored for Women. Expert Review of Cardiovascular Therapy, 6, 1123-1134. http://dx.doi.org/10.1586/14779072.6.8.1123

[7] Gerhard-Herman, M. (2002) Atherosclerosis in Women: The Role of Gender. Cardiology Rounds, 6, 1-6.

[8] Chen, J.Y., Zhang, A.D., Lu, H.Y., Guo, J., Wang, F.F. and Li, Z.C. (2013) CHADS2 versus CHA2DS2-VASc Score in Assessing the Stroke and Thromboembolism Risk Stratification in Patients with Atrial Fibrillation: A Systematic Review and Meta-Analysis. Journal of Geriatric Cardiology, 10, 258-266.

[9] Redfield, M.M., Jacobsen, S.J., Burnett Jr., J.C., Mahoney, D.W., Bailey, K.R. and Rodeheffer, R.J. (2003) Burden of Systolic and Diastolic Ventricular Dysfunction in the Community: Appreciating the Scope of the Heart Failure Epidemic. The Journal of the American Medical Association, 289, 194-202. http://dx.doi.org/10.1001/jama.289.2.194

[10] Deswal, A. and Bozkurt, B. (2006) Comparison of Morbidity in Women versus Men with Heart Failure and Preserved Ejection Fraction. The American Journal of Cardiology, 97, 1228-1231. http://dx.doi.org/10.1016/j.amjcard.2005.11.042

[11] O’Meara, E., Clayton, T., McEntegart, M.B., McMurray, J.J.V., Pina, I.L., Granger, C.B., et al. (2007) Sex Differences in Clinical Characteristics and Prognosis in a Broad Spectrum of Patients with Heart Failure: Results of the Candesartan in Heart Failure: Assessment of Reduction in Mortality and Morbidity (CHARM) Program. Circulation, 115, 31113120. http://dx.doi.org/10.1161/CIRCULATIONAHA.106.673442

[12] Silander, K., Alanne, M., Kristiansson, K., Saarela, O., Ripatti, S., Auroet, K., et al. (2008) Gender Differences in Genetic Risk Profiles for Cardiovascular Disease. PloS ONE, 3, e3615. http://dx.doi.org/10.1371/journal.pone.0003615

[13] Rosamond, W., Flegal, K., Furie, K., Go, A., Greenlund, K., Haase, N., et al. (2008) Heart Disease and Stroke Statistics-2008 Update: A Report from the American Heart Association Statistics Committee and Stroke Statistics Subcommittee. Circulation, 117, e25-e146. http://dx.doi.org/10.1161/CIRCULATIONAHA.107.187998

[14] Safar, M.E. and Smulyan, H. (2004) Hypertension in Women. American Journal of Hypertension, 17, 82-87. http://dx.doi.org/10.1016/S0895-7061(03)01008-2

[15] Kannel, W.B. (2002) The Framingham Study: Historical Insight on the Impact of Cardiovascular Risk Factors in Men versus Women. The Journal of Gender-Specific Medicine, 5, 27-37.

[16] Anand, S.S., Islam, S., Rosengren, A., Franzosi, M.G., Steyn, K., Yusufali, A.H., et al. (2008) Risk Factors for Myocardial Infarction in Women and Men: Insights from the INTERHEART Study. European Heart Journal, 29, 932-940. http://dx.doi.org/10.1093/eurheartj/ehn018

[17] Wessel, T.R., Arant, C.B., Olson, M.B., Johnson, B.D., Reis, S.E., Sharaf, B.L., et al. (2004) Relationship of Physical Fitness vs. Body Mass Index with Coronary Artery Disease and Cardiovascular Events in Women. The Journal of the American Medical Association, 292, 1179-1187. http://dx.doi.org/10.1001/jama.292.10.1179

[18] Peters, S.A., Huxley, R.R. and Woodward, M. (2014) Diabetes as a Risk Factor for Incident Coronary Heart Disease in Women Compared with Men: A Systematic Review and Meta-Analysis of 64 Cohorts including 858,507 Individuals and 28,203 Coronary Events. Diabetologia, 57, 1542-1551. http://dx.doi.org/10.1007/s00125-014-3260-6

[19] Peters, S.A., Huxley, R.R. and Woodward, M. (2014) Diabetes as a Risk Factor for Stroke in Women Compared with Men: A Systematic Review Andmeta-Analysis of 64 Cohorts, including 775,385 Individuals and 12,539 Strokes. The Lancet, 383, 1973-1980. http://dx.doi.org/10.1016/S0140-6736(14)60040-4

[20] Assaf, A.R., Parker, D., Lapane, K.L., Coccio, E., Evangelou, E. and Carleton, R.A. (2003) Does the Y Chromosome 
Make a Difference? Gender Differences in Attempts to Change Cardiovascular Risk Factors. Journal of Women's Health, 12, 321-330. http://dx.doi.org/10.1089/154099903765448835

[21] Merz, C.N.B., Shaw, L.J., Reis, S.E., Bittner, V., Kelsey, S.F., Olson, M., et al. (2006) Insights from the NHLBISponsored Women's Ischemia Syndrome Evaluation (WISE) Study: Part II: Gender Differences in Presentation, Diagnosis, and Outcome with Regard to Gender-Based Pathophysiology of Atherosclerosis and Macrovascular and Microvascular Coronary Disease. Journal of the American College of Cardiology, 47, S21-S29. http://dx.doi.org/10.1016/j.jacc.2004.12.084

[22] Shaw, L.J., Merz, C.N.B., Pepine, C.J., Reis, S.E., Bittner, V., Kelsey, S.F., et al. (2006) Insights from the NHLBISponsored Women's Ischemia Syndrome Evaluation (WISE) Study: Part I: Gender Differences in Traditional and Novel Risk Factors, Symptom Evaluation, and Gender-Optimized Diagnostic Strategies. Journal of the American College of Cardiology, 47, S4-S20. http://dx.doi.org/10.1016/j.jacc.2005.01.072

[23] DeStefano, F., Merritt, R.K., Anda, R.F., Casper, M.L. and Eaker, E.D. (1993) Trends in Nonfatal Coronary Heart Disease in the United States, 1980 through 1989. Archives of Internal Medicine, 153, 2489-2494. http://dx.doi.org/10.1001/archinte.1993.00410210117013

[24] Tobin, J.N., Wassertheil-Smoller, S., Wexler, J.P., Steingart, R.M., Budner, N., Lense, L. and Wachspress, J. (1987) Sex Bias in Considering Coronary Bypass Surgery. Annals of Internal Medicine, 107, 19-25. http://dx.doi.org/10.7326/0003-4819-107-1-19

[25] Shaw, L.J., Miller, D.D., Romeis, J.C., Kargl, D., Younis, L.T., Chaitman, B.R. (1994) Gender Differences in the Noninvasive Evaluation and Management of Patients with Suspected Coronary Artery Disease. Annals of Internal Medicine, 120, 559-566. http://dx.doi.org/10.7326/0003-4819-120-7-199404010-00005

[26] Khan, S.S., Nessim, S., Gray, R., Czer, L.S., Chaux, A. and Matloff, J. (1990) Increased Mortality of Women in Coronary Artery Bypass Surgery: Evidence for Referral Bias. Annals of Internal Medicine, 112, 561-567. http://dx.doi.org/10.7326/0003-4819-112-8-561

[27] Merz, B. (2007) New Insights into Ischemic Heart Disease in Women. Cleveland Clinic Journal of Medicine, 74, 585594. http://dx.doi.org/10.3949/ccjm.74.8.585

[28] Detrano, R.C. and Froelicher, V.F. (1988) Exercise Testing: Uses and Limitations Considering Recent Studies. Progress in Cardiovascular Diseases, 31, 837-835. http://dx.doi.org/10.1016/0033-0620(88)90015-1

[29] Lewis, J.F., McGorray, S.P. and Pepine, C.J. (2002) Assessment of Women with Suspected Myocardial Ischemia: Review of Findings of the Women's Ischemia Syndrome Evaluation (WISE) Study. Current Women's Health Reports, 2, 110-114.

[30] McSweeney, J.C., Cody, M., O’Sullivan, P., Elberson, K., Moser, D.K. and Garvin, B.J. (2003) Womens Early Warning Symptoms of Acute Myocardial Infarction. Circulation, 108, 2619-2623. http://dx.doi.org/10.1161/01.CIR.0000097116.29625.7C

[31] Blomkalns, A.L., Chen, A.Y., Hochman, J.S., Peterson, E.D., Trynosky, K., Diercks, D.B., et al. (2005) Gender Disparities in the Diagnosis and Treatment of Non-ST-Segment Elevation Acute Coronary Syndromes: Large-Scale Observations from the CRUSADE (Can Rapid Risk Stratification of Unstable Angina Patients Suppress Adverse Outcomes with Early Implementation of the American College of Cardiology/American Heart Association Guidelines) National Quality Improvement Initiative. Journal of the American College of Cardiology, 45, 832-837. http://dx.doi.org/10.1016/j.jacc.2004.11.055

[32] Gulati, M., Cooper-DeHoff, R.M., McClure, C., Johnson, B.D., Shaw, L.J., Handberg, E.M., et al. (2009) Adverse Cardiovascular Outcomes in Women with Nonobstructive Coronary Artery Disease: A Report from the Women's Ischemia Syndrome Evaluation Study and the St James Women Take Heart Project. Annals of Internal Medicine, 169, 843-850. http://dx.doi.org/10.1001/archinternmed.2009.50

[33] Wong, T.Y., Klein, R., Sharrett, A.R., Schmidt, M.I., Pankow, J.S., Couper, D.J., et al. (2002) Retinal Arteriolar Narrowing and Risk of Diabetes Mellitus in Middle-Aged Persons. Journal of the American Medical Association, 287, 2528-2533. http://dx.doi.org/10.1001/jama.287.19.2528

[34] Burke, A.P., Farb, A., Malcom, G.T., Liang, Y., Smialek, J. and Virmani, R. (1998) Effect of Risk Factors on the Mechanism of Acute Thrombosis and Sudden Coronary Death in Women. Circulation, 97, 2110-2116. http://dx.doi.org/10.1161/01.CIR.97.21.2110

[35] Han, S.H., Bae, J.H., Holmes, D.R., , Lennon, R.J., Eeckhout, E., Barsness, G.W., et al. (2008) Sex Differences in Atheroma Burden and Endothelial Function in Patients with Early Coronary Atherosclerosis. European Heart Journal, 29, 1359-1369. http://dx.doi.org/10.1093/eurheartj/ehn142

[36] Guagliumi, G., Capodanno, D., Saia, F., Musumeci, G., Tarantini, G., Garbo, R., et al. (2014) Mechanisms of Atherothrombosis and Vascular Response to Primary Percutaneous Coronary Intervention in Women versus Men with Acute Myocardial Infarction: Results of OCTAVIA (Optimal Coherence Tomography Assessment of Gender Diversity in Primary Angioplasty) Study. Journal of American College of Cardiology Intervention, 7, in Press. 
[37] Celermaier, D.S., Sorenson, K.E., Spiegelhalter, D.J., Georgakopoulos, D., Robinson, J. and Deanfield, J.E. (1994) Aging Is Associated with Endothelial Dysfunction in Healthy Men Years before the Age-Related Decline in Women. Journal of the American College of Cardiology, 24, 471-476. http://dx.doi.org/10.1016/0735-1097(94)90305-0

[38] Jensen, U. and Johansson, J. (2001) Gender Difference in Age-Related Changes in Vascular Function. Journal of Internal Medicine, 250, 29-36. http://dx.doi.org/10.1046/j.1365-2796.2001.00843.x

[39] Skaug, E., Madssen, E., Aspenes, S.T., Wisloff, U. and Ellingsen, O. (2014) Cardiovascular Risk Factors Have a Large Impact on Endothelial Function in Self-Reported Healthy Women than Men in the HUNT3 Fitness Study. PLoS ONE, 9, e101371. http://dx.doi.org/10.1371/journal.pone.0101371

[40] Modena, M.G., Bonetti, L., Coppi, F., Bursi, F. and Rossi, R. (2002) Prognostic Role of Reversible Endothelial Dysfunction in Hypertensive Postmenopausal Women. Journal of the American College of Cardiology, 40, 505-510. http://dx.doi.org/10.1016/S0735-1097(02)01976-9

[41] Pearson, T.A., Blair, S.N., Daniels, S.R., Eckel, R.H., Fair, J.M., Fortmann, S.P., et al. (2002) AHA Guidelines for Primary Prevention of Cardiovascular Disease and Stroke: 2002 Update: Consensus Panel Guide to Comprehensive Risk Reduction for Adult Patients without Coronary or Other Atherosclerotic Vascular Disease. Circulation, 106, 338391. http://dx.doi.org/10.1161/01.CIR.0000020190.45892.75

[42] Paffenbarger, R.S., Hyde, R., Wing, A.L. and Hsieh, C.-C. (1986) Physical Activity and All-Cause Mortality and Longevity of College Alumni. New England Journal of Medicine, 314, 605-613. http://dx.doi.org/10.1056/NEJM198603063141003

[43] Kikkinos, P. and Meyers, J. (2010) Exercise and Physical Activity: Clinical Outcomes and Applications. Circulation, 122, 1637-1648. http://dx.doi.org/10.1161/CIRCULATIONAHA.110.948349

[44] Lee, I.M., Rexrode, K.M., Cook, N.R., Manson, J.E. and Buring, J.E. (2001) Physical Activity and Coronary Heart Disease in Women: Is “No Pain, No Gain” Passé? Journal of the American Medical Association, 285, 1447-1454. http://dx.doi.org/10.1001/jama.285.11.1447

[45] Gregg, E.W., Cauley, J.A., Stone, K., Thompson, T.J., Bauer, D.C., Cummings, S.R., et al. (2003) Relationship of Changes in Physical Activity and Mortality among Older Women. Journal of the American Medical Association, 289, 2379-2386. http://dx.doi.org/10.1001/jama.289.18.2379

[46] Mora, S., Redberg, R.F., Cui, Y., Whiteman, M.K., Flaws, J.A., Sharrett, A.R. and Blumenthal, R.S. (2003) Ability of Exercise Testing to Predict Cardiovascular and All-Cause Death in Asymptomatic Women: A 20-Year Follow-Up of the Lipid Research Clinics Prevalence Study. Journal of the American Medical Association, 290, 1600-1607. http://dx.doi.org/10.1001/jama.290.12.1600

[47] Gulati, M., Pandey, D.K., Arnsdorf, M.F., Lauderdale, D.S., Thisted, R.A., Wicklund, R.H., et al. (2003) Exercise Capacity and Risk of Death in Women: St. James Women Take Heart Project. Circulation, 108, 1554-1559. http://dx.doi.org/10.1161/01.CIR.0000091080.57509.E9

[48] Powell, K.E., Thompson, P.D., Caspersen, C.J. and Kendricks, J.S. (1987) Physical Activity and the Incidence of Coronary Heart Disease. Annual Review of Public Health, 8, 253-287.

[49] Berlin, R.R., Pratt, M. and Blair, S.N. (1990) A Meta-Analysis of Physical Activity in the Prevention of Coronary Heart Disease. American Journal of Epidemiology, 132, 612-628.

http://dx.doi.org/10.1146/annurev.pu.08.050187.001345

[50] Barnes, A.S. (2012) Obesity and Sedentary Lifestyles: Risk for Cardiovascular Disease in Women. Texas Institute Journal, 39, 224-227.

[51] Zang, C., Rexrode, K.M., Van Dam, R.M., Li, T. and Hu, F.B. (2008) Abdominal Obesity and the Risk of All-Cause, Cardiovascular, and Cancer Mortality: Sixteen Years of Follow-Up in US Women. Circulation, 117, 1658-1667. http://dx.doi.org/10.1161/CIRCULATIONAHA.107.739714

[52] Lovejoy, J.C., Champagne, C.M., De Jonge, L., Xie, H. and Smith, S.R. (2008) Increased Visceral Fat and Decreased Energy Expenditure during the Menopausal Transition. International Journal of Obesity, 32, 949-958. http://dx.doi.org/10.1038/ijo.2008.25

[53] Chandra, A., Neeland, I.J., Berry, J.D., Ayers, C.R., Rohatgi, A., Das, S.R., et al. (2014) The Relationship of Body Mass and Fat Distribution with Incident Hypertension: Observations from the Dallas Heart Study. Journal of the American College Cardiology, 64, 997-1002. http://dx.doi.org/10.1016/j.jacc.2014.05.057

[54] Slentz, C.A., Aiken, L.B., Houmard, J.A., Bales, C.W., Johnson, J.L., Tanner, C.J., et al. (2005) Inactivity, Exercise, and Visceral Fat. STRRIDE: A Randomized, Controlled Study of Exercise Intensity and Amount. Journal of Applied Physiology, 99, 1613-1618. http://dx.doi.org/10.1152/japplphysiol.00124.2005

[55] Schmitz, K.H., Hannan, P.J., Stovitz, S.D., Bryan, C.J., Warren, M. and Jensen, M.D. (2007) Strength Training and Adiposity in Premenopausal Women: Strong, Healthy, and Empowered Study. The American Journal of Clinical Nutrition, 86, 566-572. http://dx.doi.org/10.1519/JSC.0b013e3181fb4a46 
[56] Vispute, S.S., Smith, J.D., Le Cheminant, J.D. and Hurley, K.S. (2011) The Effect of Abdominal Exercise on Abdominal Fat. The Journal of Strength Conditioning Research, 25, 2559-2564.

[57] Chiuve, S.E., Fung, T.T., Rexrode, K.M., Spiegelman, D., Manson, J.E., Stampfer, M.J. and Albert, C.M. (2011) Adherence to a Low-Risk Healthy Lifestyle and Risk of Sudden Cardiac Death among Women. Journal of the American Medical Association, 306, 62-69. http://dx.doi.org/10.1001/jama.2011.907

[58] Hu, F.R., Willett, W.C., Li, T., Stampfer, M.J., Colditz, G.A. and Manson, J.E. (2004) Adiposity as Compared with Physical Activity in Predicting Mortality among Women. New England Journal of Medicine, 351, 2694-2703. http://dx.doi.org/10.1056/NEJMoa042135

[59] Blair, S.N., Kohl 3rd, H.W., Paffenbarger Jr., R.S., Clark, D.G., Cooper, K.H. and Gibbons, L.W. (1989) Physical Fitness and All-Cause Mortality: A Prospective Study of Healthy Men and Women. Journal of the American Medical Association, 262, 2395-2401. http://dx.doi.org/10.1001/jama.1989.03430170057028

[60] Sattelmair, J., Pertman, J., Ding, E.L., Kohn, H.W., Haskell, W. and Lee, I.M. (2011) Dose Response between Physical Activity and Risk of Coronary Heart Disease: A Meta-Analysis. Circulation, 124, 789-795. http://dx.doi.org/10.1161/CIRCULATIONAHA.110.010710

[61] Manson, J.E., Greenland, P., LaCroix, A.Z., Stefanick, M.L., Mouton, C.P., Oberman, A., et al. (2002) Walking Compared with Vigorous Exercise for the Prevention of Cardiovascular Events in Women. New England Journal of Medicine, 347, 716-725. http://dx.doi.org/10.1056/NEJMoa021067

[62] Luke, A., Dugas, L.R., Durazo-Arvizu, R.A.,Cao, G. and Cooper, R.S. (2001) Assessing Physical Activity and Its Relationship to Cardiovascular Risk Factors: NHANES 2003-2006. BMC Public Health, 11, 387. http://dx.doi.org/10.1186/1471-2458-11-387

[63] Rossouw, J.E., Anderson, G.L., Prentice, R.L., LaCroix, A.Z., Kooperberg, C., Stefanick, M.L., et al. (2002) Risks and Benefits of Estrogen plus Progestin in Healthy Postmenopausal Women: Principal Results from the Women's Health Initiative Randomized Controlled Trial. Journal of the American Medical Association, 288, 321-333. http://dx.doi.org/10.1001/jama.288.3.321

[64] Grady, D., Herrington, D., Bittner, V., Blumenthal, R., Davidson, M., Hlatky, M., et al. (2002) Cardiovascular Disease Outcomes during 6.8 Years of Hormone Therapy: Heart and Estrogen/Progestin Replacement Study Follow-Up (HERS II). Journal of the American Medical Association, 288, 49-57. http://dx.doi.org/10.1001/jama.288.1.49

[65] Cherry, N., Gilmour, K., Hannaford, P., Heagerty, A., Khan, M.A., Kitchener, H., et al. (2002) Oestrogen Therapy for Prevention of Reinfarction in Postmenopausal Women: A Randomized Placebo Controlled Trial. The Lancet, 360, 2001-2008. http://dx.doi.org/10.1016/S0140-6736(02)12001-0

[66] Schierbeck, L.L., Rejnmark, L., Tofteng, C.L., Stilgren, L., Eiken, P., Mosekilde, L., et al. (2012) Effect of Hormone Replacement Therapy on Cardiovascular Events in Recently Postmenopausal Women: Randomized Trial. British Medical Journal, 345, Article ID: e6409. http://dx.doi.org/10.1136/bmj.e6409 
Scientific Research Publishing (SCIRP) is one of the largest Open Access journal publishers. It is currently publishing more than 200 open access, online, peer-reviewed journals covering a wide range of academic disciplines. SCIRP serves the worldwide academic communities and contributes to the progress and application of science with its publication.

Other selected journals from SCIRP are listed as below. Submit your manuscript to us via either submit@scirp.org or Online Submission Portal.
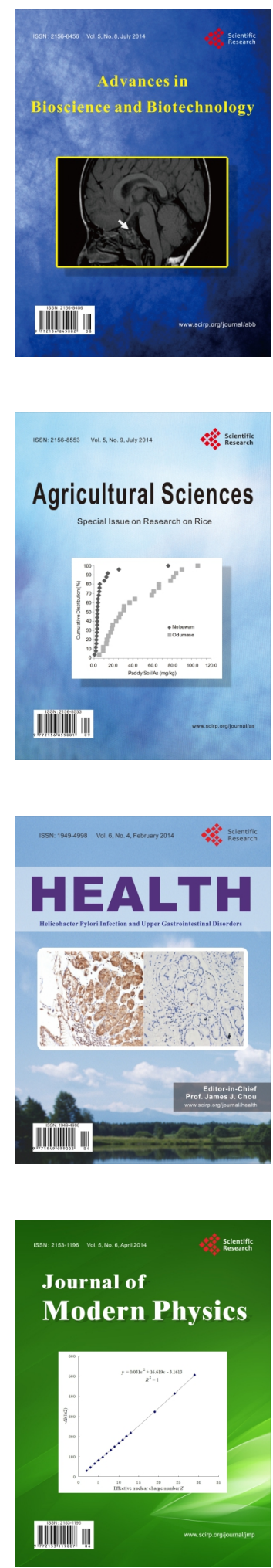
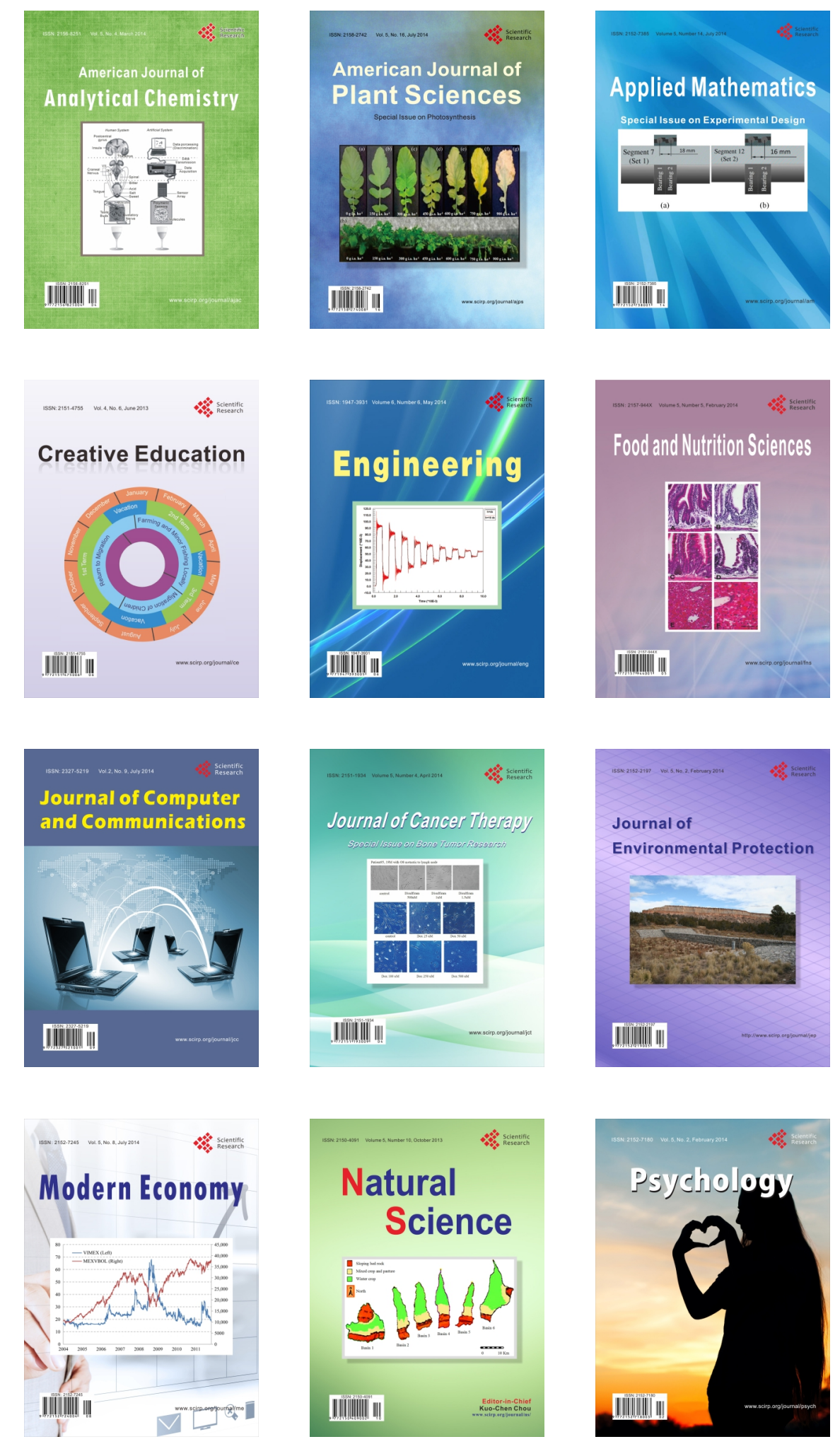